\title{
Autonomic Dysfunction in Parkinson's Disease
}

\author{
Ronald F. Pfeiffer ${ }^{1}$ (i)
}

Published online: 13 August 2020

(C) The American Society for Experimental NeuroTherapeutics, Inc. 2020

\begin{abstract}
Recognition of the importance of nonmotor dysfunction as a component of Parkinson's disease has exploded over the past three decades. Autonomic dysfunction is a frequent and particularly important nonmotor feature because of the broad clinical spectrum it covers. Cardiovascular, gastrointestinal, urinary, sexual, and thermoregulatory abnormalities all can appear in the setting of Parkinson's disease. Cardiovascular dysfunction is characterized most prominently by orthostatic hypotension. Gastrointestinal dysfunction can involve virtually all levels of the gastrointestinal tract. Urinary dysfunction can entail either too frequent voiding or difficulty voiding. Sexual dysfunction is frequent and frustrating for both patient and partner. Alterations in sweating and body temperature are not widely recognized but often are present. Autonomic dysfunction can significantly and deleteriously impact quality of life for individuals with Parkinson's disease. Because effective treatment for many aspects of autonomic dysfunction is available, it is vitally important that assessment of autonomic dysfunction be a regular component of the neurologic history and exam and that appropriate treatment be initiated and maintained.
\end{abstract}

Key Words Autonomic · gastrointestinal · orthostatic hypotension · urinary $\cdot$ erectile dysfunction $\cdot$ thermoregulatory

\section{Introduction}

Recognition of the role of nonmotor features in Parkinson's disease (PD) has increased exponentially over the past 30 years, and autonomic dysfunction has emerged as an important aspect of nonmotor dysfunction, evident in both the early and later stages of PD. Autonomic dysfunction in PD covers a broad spectrum that includes cardiovascular, gastrointestinal, urological, sexual, and thermoregulatory dysfunctions (Table 1). Early surveys suggested the widespread presence of autonomic dysfunction in PD [1], and this has been confirmed by subsequently larger and more sophisticated studies [2]. Autonomic dysfunction can be present at all stages of PD. In one study in which 112 patients with early (Hoehn/Yahr stage 1) PD were enrolled, at least one autonomic symptom already was evident in $71 \%$ at the baseline examination and in $100 \% 3$ years later [3]. Recent studies suggest that earlier development of

Electronic supplementary material The online version of this article (https://doi.org/10.1007/s13311-020-00897-4) contains supplementary material, which is available to authorized users.

Ronald F. Pfeiffer

pfeiffro@ohsu.edu

1 Department of Neurology, Oregon Health \& Science University, 3181 SW Sam Jackson Park Road, Portland, OR 97239-3098, USA autonomic dysfunction in PD is associated with more rapid disease progression and shorter survival time $[4,5]$. Both sympathetic and parasympathetic involvements are present in PD, and pathology involves both peripheral and central components of the autonomic nervous system [6].

A variety of scales have been developed and validated to assess nonmotor dysfunction in PD and include questions regarding autonomic function. The Non-Motor Symptoms Questionnaire (NMSQuest) is used for screening purposes, whereas the Non-Motor Symptoms Scale (NMSS) is designed to assess nonmotor symptom burden [7]. The Scales for Outcomes in Parkinson's Disease-Autonomic (SCOPAAUT) specifically addresses autonomic dysfunction in PD and is perhaps the most frequently used scale for this purpose. Other scales have been developed for the assessment of individual features of autonomic dysfunction but, generally, have not been validated specifically for PD $[8,9]$. The Movement Disorder Society-Unified Parkinson's Disease Rating Scale (MDS-UPDRS) contains questions pertaining to autonomic dysfunction, some of which correlate well with the SCOPAAUT [10]. The NINDS Common Data Elements (www.commondataelements.ninds.nih.gov>Parkinson's) is a source for additional information regarding scales for the assessment of various features of PD, including autonomic dysfunction [11]. 
Table 1 Clinical manifestations of autonomic dysfunction in Parkinson's disease

\begin{tabular}{l}
\hline Cardiovascular dysfunction \\
Orthostatic hypotension \\
Supine hypertension \\
Postprandial hypotension \\
Gastrointestinal dysfunction \\
Excessive saliva/drooling \\
Dysphagia \\
Gastroparesis \\
Small intestinal dysfunction \\
Slowed transit \\
Small intestinal bacterial overgrowth \\
Bowel dysfunction \\
Decreased frequency/slow transit \\
constipation \\
Defecatory dysfunction \\
Urinary dysfunction \\
Overactive bladder symptoms \\
Underactive/obstructive bladder \\
symptoms \\
Sexual dysfunction \\
Erectile dysfunction \\
Decreased libido \\
Restless genital syndrome \\
Thermoregulatory dysfunction \\
Heat/cold intolerance \\
Hyperhidrosis/hypohidrosis \\
Acute hyperthermia \\
\hline
\end{tabular}

\section{Cardiovascular Dysfunction}

Cardiovascular autonomic dysfunction in PD may be characterized by both preganglionic (baroreflex failure) and postganglionic (sympathetic denervation) lesions, and it is the combination of these two that leads to the development of neurogenic orthostatic hypotension $(\mathrm{nOH})$ in patients with PD [12]. Cardiac sympathetic denervation clearly is evident in PD [13] and can be visualized by both $\mathrm{I}^{123}$-meta-iodobenzylguanidine ( $\left.\mathrm{I}^{123}-\mathrm{MIBG}\right)$ imaging [14] and ${ }^{18}$ fluoro-dopamine PET imaging [15], which can be very useful in distinguishing between PD and multiple system atrophy (MSA), since both $\mathrm{I}^{123}$-MIBG imaging and ${ }^{18}$ fluoro-dopamine PET imaging typically are normal in MSA but abnormal in PD $[15,16]$. Cardiac denervation by itself, however, does not appear to be responsible for the blood pressure irregularities that characterize PD $[12,17,18]$. Cardiovascular abnormalities described in PD include not only $\mathrm{nOH}$ but also supine hypertension and postprandial hypotension.

\section{Orthostatic Hypotension}

Orthostatic hypotension $(\mathrm{OH})$ has been defined by consensus as a sustained decrease in systolic blood pressure of $\geq$
$20 \mathrm{mmHg}$ or in diastolic blood pressure of $\geq 10 \mathrm{mmHg}$ within 3 min of standing or at $60^{\circ}$ or greater head-up tilt during formal tilt table testing [19-21]. Some centers, when performing tilt testing, utilize a systolic drop of $\geq 30 \mathrm{mmHg}$ and a systolic drop of $\geq 15 \mathrm{mmHg}$ as a cutoff because the tilt table eliminates the muscle pumping action of the legs that normally is present during active standing [21]. In routine clinic settings, in which supine-to-standing pressure measurements may not be practical, sitting-to-standing measurement is a reasonable, though somewhat less sensitive, alternative in which cutoff values of $\geq 15 \mathrm{mmHg}$ systolic and $\geq 7 \mathrm{mmHg}$ diastolic may be appropriate [22]. In some patients, the drop in blood pressure and consequent symptoms do not occur within the first 3 min after standing, but develop later. This is labeled delayed $\mathrm{OH}$ and may be a precursor to the eventual development of classic $\mathrm{OH}[20,23]$.

$\mathrm{OH}$ can be produced by non-neurogenic factors such as hypovolemia, cardiac pump failure, or vasodilating and diuretic medications. However, in $\mathrm{PD}$, neurogenic $\mathrm{OH}(\mathrm{nOH})$ typically is present, with inadequate neurocirculatory responses to postural change due to baroreflex failure and impaired release of norepinephrine [20]. It is important to differentiate between the two mechanisms, since treatment differs. Perhaps the most practical distinguishing point is that in nonneurogenic $\mathrm{OH}$, the heart rate shows a pronounced increase upon standing ( $\geq 15 \mathrm{bpm}$ ), whereas in $\mathrm{nOH}$, any increase is mild or absent [24]. Additional distinguishing features are described by Palma and Kaufmann in their review [21].

Reports of the prevalence of $\mathrm{OH}$ in PD cover a wide range, but a systematic review and meta-analysis have provided a figure of $30 \%$ [25]. Although the prevalence of $\mathrm{OH}$ in $\mathrm{PD}$ increases with age and disease duration [21], multiple studies have documented that $\mathrm{OH}$ may first appear early in the course of PD [26, 27]. It is important to remember that not all individuals with $\mathrm{PD}$ and $\mathrm{nOH}$ experience symptoms. In one study, only one third of PD patients with documented nOH were experiencing symptoms [28]; in another, 62\% were [29]. Conversely, it has been reported that over $30 \%$ of individuals with PD may experience orthostatic intolerance, in which they display symptoms of $\mathrm{OH}$ without demonstrating changes in blood pressure [30].

The most frequent symptom experienced by patients with $\mathrm{nOH}$ is lightheadedness upon standing. This may be slight and transient, or it may progress to the point of syncope; it can appear shortly after standing or in a more delayed fashion. Disturbances in vision; clouded thinking; pain involving the head, neck, and shoulders (coat-hanger headache); low back or buttock pain; shortness of breath; or simply a feeling of lethargy all may be manifestations of $\mathrm{nOH}$. Recurrent falling, even without syncope or even lightheadedness, has been attributed to $\mathrm{nOH}[24,31]$. It also has been suggested that $\mathrm{nOH}$ confers an increased risk of the development of cognitive impairment in individuals with PD [32] and that the mere 
presence of $\mathrm{nOH}$ increases the risk of functional disability, even if symptoms are not present [29].

Both nonpharmacologic and pharmacologic treatment approaches are employed in the treatment of $\mathrm{nOH}$. Drugs that may be precipitating or magnifying the orthostatic changes, such as diuretics, vasodilators, tricyclics, and drugs that antagonize norepinephrine function, should be eliminated or have their dosage reduced, if possible. Once that is done, nonpharmacologic approaches should be considered before any pharmacologic treatment is initiated. Liberalizing both fluid and salt intake may be sufficient for some individuals. Fluid intake should be maintained at 2 to $2.5 \mathrm{~L} /$ day [21]. Individuals with $\mathrm{nOH}$ should avoid activities and situations that can increase body temperature, such as high-intensity exercise, hot tubs or saunas, prolonged hot showers, and prolonged exposure to high environmental temperature [24]. Methods to decrease venous pooling can be useful. Compression stockings, when fitted properly, are effective but can be uncomfortable to wear, and PD patients with motor impairment may require assistance getting them on and off. Knee-high stockings generally are ineffective; waist-high stockings are effective, but poorly tolerated [24], with the result that they often end up in the drawer rather than on the patient. Because the splanchnic venous vascular bed accounts for 20 to $30 \%$ of total blood volume and, thus, is the largest of the body's blood reservoirs [33], abdominal binders and compression shorts are effective alternatives that are easier to utilize and tolerate than compression stockings [20,34]. Drinking two 8-oz glasses of cold water in quick succession can elevate systolic pressure by $20 \mathrm{mmHg}$ for $1-2 \mathrm{~h}$ and, thus, can be employed prior to planned activities [35]. Actions that increase total peripheral resistance, such as crossing the legs and squeezing, standing up on the toes, or repetitively contracting the gluteal muscles for $30 \mathrm{~s}$, also can reduce nOH [35]. Sleeping with the head of the bed elevated $30^{\circ}$ may reduce the risk of symptomatic $\mathrm{nOH}$ when first arising in the morning.

Pharmacologic treatment of $\mathrm{nOH}$, with the aim of increasing intravascular volume or increasing vasomotor tone can be employed when nonpharmacologic methods are insufficiently effective (Table 2). Fludrocortisone has long been used to treat $\mathrm{nOH}$, typically at a dose of $0.1 \mathrm{mg}$ once or twice daily. However, particularly for the elderly, adverse effects can pose difficulties [36]. Supine hypertension, especially at night, is a potential complication of fludrocortisone therapy; therefore, if a twice-daily regimen is being used, the last dose should be given in the early afternoon. Fludrocortisone also can produce lower extremity edema. Most significantly, fludrocortisone may precipitate congestive heart failure. Therefore, it is not appropriate for use in persons with a prior history of heart failure. Since fludrocortisone also can induce hypokalemia, potassium supplementation and monitoring of serum potassium levels should be considered. Midodrine is a prodrug whose metabolite, desglymidodrine, is an alpha-1 receptor agonist that increases vascular resistance and vasomotor tone [24]. It typically is administered in one to three doses per day, with a maximum dose of $45 \mathrm{mg}$ daily. Like fludrocortisone, midodrine also has a propensity to produce nocturnal supine hypertension [37], and limitations regarding the final dose of the day are similar to those of fludrocortisone. Other potential adverse effects of midodrine include urinary retention, itching of the scalp, other paresthesias, and piloerection [38]. Droxidopa is a prodrug that is converted into norepinephrine [24]. It has a longer duration of action than midodrine (6-8 h vs 2-4 h) but, typically, still is administered three times daily, with the third dose in the mid-afternoon and a maximum dose of $1800 \mathrm{mg}$ daily. Supine hypertension again is a risk, although significant nocturnal blood pressure increases with droxidopa may be relatively infrequent, in the range of 10 to $20 \%$ of patients treated $[37,39]$. Although droxidopa is converted to norepinephrine by the enzyme aromatic amino acid decarboxylase (AADC), which is the enzyme that is blocked by carbidopa, it appears that the carbidopa doses typically employed in conjunction with levodopa administration do not block the vasopressor effect of droxidopa to a clinically significant degree [40]. Cognitive and behavioral effects, such as confusion, agitation, fear, manic behavior, irritability, perseveration, and memory impairment, have been reported in individuals taking droxidopa, possibly as a consequence of excessive activity within noradrenergic networks in the central nervous system [41]. Pyridostigmine, an acetylcholinesterase inhibitor, can modestly reduce $\mathrm{nOH}$ without exacerbating supine hypertension, but it is not widely utilized. Desmopressin, octreotide, methylphenidate, and yohimbine can be used in refractory or special circumstances [42].

\section{Supine Hypertension}

Blood pressure typically drops by 10 to $20 \%$ at night $[43,44]$. However, approximately $50 \%$ of individuals with $\mathrm{nOH}$ experience an increase in their blood pressure when supine [45]. Studies suggest that supine hypertension is evident in 34 to $46 \%$ of PD patients [46, 47]. It has been defined by consensus criteria as a blood pressure $\geq 140$ systolic and/or $\geq 90$ diastolic after at least $5 \mathrm{~min}$ of rest in the supine position [45]. For some patients, 24-h ambulatory blood pressure monitoring may be very helpful in documenting the presence and severity of both $\mathrm{nOH}$ and supine hypertension. The decision whether or not to treat supine hypertension in an individual with PD who also experiences $\mathrm{nOH}$ during the daytime hours is a very difficult one. Because the consequences of $\mathrm{nOH}$, such as falling and syncope, are more immediate and acutely dangerous than the delayed potential complications of supine hypertension [32], many neurologists lean toward accepting some degree of supine hypertension in order to limit daytime $\mathrm{nOH}$, but if the supine hypertension is prominent enough (e.g., systolic pressure greater than 160- 
Table 2 Pharmacologic management of orthostatic hypotension

\begin{tabular}{lll}
\hline Drug & Mechanism & Dosage \\
\hline $\begin{array}{l}\text { Primary choices } \\
\text { Midodrine } \\
\text { Droxidopa }\end{array}$ & $\alpha_{1}$-Adrenoreceptor agonist & \\
Secondary choices & Norepinephrine prodrug & $7.5-30 \mathrm{mg}$ daily \\
Fludrocortisone & Mineralocorticoid & $300-1800 \mathrm{mg}$ daily \\
Pyridostigmine & Acetylcholinesterase inhibitor & \\
Consider in refractory situation & (inadequately tested) & $0.1-0.4 \mathrm{mg}$ daily \\
Desmopressin & Vasopressin receptor agonist & $60-180 \mathrm{mg}$ daily \\
Octreotide & Somatostatin receptor agonist & \\
Methylphenidate & Norepinephrine/dopamine reuptake inhibitor & $2-4 \mu \mathrm{g}$ daily (i.m.) \\
Yohimbine & $\alpha_{2}$-Adrenoreceptor antagonist & $12.5-25 \mu \mathrm{g}$ daily \\
Indomethacin & Prostaglandin synthesis inhibitor & $15-30 \mathrm{mg}$ daily \\
\hline
\end{tabular}

180), treatment becomes necessary. Nonpharmacologic treatment approaches, such as elevating the head of the bed by 4 6 in. when supine, should be utilized first, but if pharmacologic treatment becomes necessary, short-acting drugs, such as an angiotensin-converting enzyme inhibitor (captopril), a central $\alpha-2$ agonist (clonidine), an angiotensin II receptor antagonist (losartan), or vasodilator (transdermal nitroglycerin or hydralazine), can be administered as a single bedtime dose [24, 32]. An advantage of transdermal nitroglycerin is that its effect can be terminated very quickly by removing the patch [42]. The cyclic guanosine monophosphate (cGMP)-specific phosphodiesterase type 5 inhibitor, sildenafil, has been reported to reduce supine hypertension in individuals with pure autonomic failure and multiple system atrophy, but this was not studied in PD itself $[48,49]$.

\section{Postprandial Hypotension}

Postprandial hypotension and exercise-induced hypotension may occur in the setting of PD. Postprandial hypotension is particularly likely to occur after consuming large, carbohydrate-heavy meals and may develop within 15 min after eating and persist for up to $3 \mathrm{~h}$. Elderly PD patients may be most susceptible to this phenomenon. Constipation, preprandial hypertension at rest, and orthostatic hypotension best predict the presence of postprandial hypotension in elderly PD patients [47]. The risk of postprandial hypotension can be reduced by reducing carbohydrate intake and eating smaller, more frequent meals. With regard to exercise-induced hypotension, performing exercises in a sitting position or in a swimming pool can circumvent the drop in blood pressure [21].

\section{Gastrointestinal Dysfunction}

In 1991, Edwards and colleagues [50] surveyed gastrointestinal (GI) symptoms in 98 patients with PD and 50 comparably aged control subjects and identified five features as characteristic of GI dysfunction in PD: salivary excess, difficulty swallowing, nausea (attributed to impaired gastric emptying when not medication induced), decreased bowel movement frequency, and difficulty with the act of defecation itself. Others subsequently confirmed and expanded these findings [2]. Although much has been written in recent years regarding the possible role of the enteric nervous system and the gut microbiome in the etiology and pathogenesis of PD, the following will focus on clinical management of the identified GI symptoms.

\section{Excess Saliva}

Older studies have reported the presence of excess saliva or drooling in over $70 \%$ of persons with PD, with an even higher percentage in those with advanced PD [51]. In a recent large retrospective analysis of a longitudinal cohort of 728 patients with PD, however, the prevalence of subjective drooling was $37 \%$ at the time of baseline analysis, increasing only to $40 \%$ with the passage of time [52]. In this cohort, the presence of drooling was highest (40\%) in patients over age 80 and lowest in individuals younger than age 50 (24\%). The presence of drooling was associated with dysphagia and with cognitive decline. Salivary excess and drooling are not due to excess saliva production, but rather to less frequent and more inefficient swallowing, reduced lip seal, and changes in posture and awareness $[52,53]$; in fact, salivary production typically is reduced in $\mathrm{PD}$.

Chewing gum or sucking on hard candy, which converts swallowing into a more conscious action, can be a fugacious, but practical, measure to relieve drooling in some social situations. Most treatment efforts, however, are aimed at reducing saliva production. Anticholinergic drugs, such as trihexyphenidyl, reduce saliva production but are problematic for individuals with PD because of the risk of producing 
urinary retention, constipation, and memory impairment. The anticholinergic glycopyrrolate circumnavigates the risk of cognitive impairment because it does not cross the bloodbrain barrier, but it still can produce peripherally mediated adverse effects such as urinary retention and constipation. Sublingual administration of $1 \%$ atropine eye drops, one drop once or twice daily, may reduce saliva production while avoiding systemic anticholinergic effects [54]. However, intraparotid injection of botulinum toxin, either type A or type $\mathrm{B}$, has now become the primary treatment approach to treating troublesome drooling in persons with PD by reducing saliva production, typically producing benefit that persists for 3 months or more [55-58].

\section{Dysphagia}

Reports of the prevalence of dysphagia in PD show great variability [59], but a meta-analysis by Kalf and colleagues [60] arrived at a pooled prevalence estimate of 35\% for subjective dysphagia and a pooled estimate of $82 \%$ for dysphagia identified by objective testing, which suggests that patients with PD often are unaware their swallowing is impaired; moreover, the risk of dysphagia in PD patients was three times that in control individuals [60]. Although more likely to be present in patients with advanced $\mathrm{PD}$, dysphagia may develop early in the course of PD [61]. Dysphagia increases the risk of malnourishment and malnutrition in patients with PD [62], and dysphagia severity predicts a poor outcome in persons with advanced PD [63]. Dysphagia for pills is an often overlooked aspect of dysphagia in PD and may be evident in close to $30 \%$ of patients, particularly those with more advanced disease [64]. Capsules are swallowed most readily; oval tablets pose the most difficulty [64]. One very important and significant risk of dysphagia is aspiration with consequent pneumonia. Some degree of aspiration is present in 15 to $56 \%$ of patients with PD [65]. An abnormal tendency to swallow during inspiration rather than exhalation may be evident in PD patients and increase their risk of aspiration [66].

Dysphagia can be the consequence of dysfunction at the oral, pharyngeal, or esophageal levels [65]. The standard screening evaluation for dysphagia in PD has been the modified barium swallow study (MBSS), but it is important to remember that the MBSS primarily assesses oral and pharyngeal function and does not fully evaluate the entire extent of esophagus. Therefore, if the MBSS does not provide an explanation for dysphagia in a patient, video fluoroscopy should be employed to evaluate for processes involving the esophagus, such as esophageal dysmotility, Zenker's diverticulum, cricopharyngeal bar formation, anterior cervical osteophyte formation, achalasia, and lower esophageal sphincter dysfunction [67]. A variety of additional tests may be useful in evaluating dysphagia in the setting of PD [68]. Handheld Cough Testing (HCT) recently has been reported to be a simple and highly sensitive screening test for dysphagia in PD patients [69]. HCT employs a relatively inexpensive and portable system consisting of a facemask coupled to a handheld nebulizer and an analog peak flow meter and measures cough airflow and sensation during voluntary and reflex cough tasks. Reduced reflex cough airflow below a designated level predicts the presence of dysphagia and airway penetration [69].

Whether dysphagia in PD responds to levodopa therapy remains controversial $[70,71]$. In one recent retrospective study, transdermal rotigotine was reported to improve dysphagia in both drug-naïve PD patients and as add-on therapy, but further investigation of this clearly is needed [72]. Behavioral approaches that teach safe swallowing techniques remain the standard approach for the treatment of dysphagia. A variety of additional treatment techniques have been described. Expiratory muscle strength training (EMST) may be effective in improving swallowing safety in patients with PD [73], and the combination of postural techniques and EMST is even more effective [74]. Respiratory-swallow coordination training (RSCT) in combination with voluntary cough skill training (VCST) also has been reported to be effective in a recent single case report [75]. Improvement not only in speech but also in both subjective and some videofluoroscopic parameters of swallowing persisted up to 6 months following a course of Lee Silverman Voice Treatment (LSVT-LOUD) in a group of patients with mild PD [76]. Improvement in dysphagia has been noted following subthalamic deep brain stimulation surgery [77], although deterioration in swallowing also may occur [78]. Improvement with high-frequency repetitive transcranial magnetic stimulation (rTMS) in a double-blind, randomized trial involving 33 PD patients, as assessed by both questionnaires and videofluoroscopic examination, also has been described [79]. Cricopharyngeal dysfunction may be successfully treated with either myotomy or botulinum toxin injections $[80,81]$.

\section{Gastroparesis}

Impaired gastric emptying, or gastroparesis, can be characterized by a variety of symptoms that include nausea, vomiting, early satiety, postprandial fullness, and upper abdominal pain [82]. The exact prevalence of gastroparesis in PD remains unclear [83]. However, in a retrospective cohort study in which 65 PD patients with GI symptoms underwent both wireless motility capsule evaluation and lactulose breath testing, delayed gastric emptying was present in 35\% [84]. Gastroparesis may be present throughout the entire spectrum of PD, including in individuals with early, untreated disease [85]. Gastroparesis not only may produce uncomfortable symptoms in those afflicted, but in individuals with PD, it also can impair the effectiveness of the levodopa they may be taking. Since levodopa is primarily absorbed in the proximal small intestine, delayed gastric emptying can result in a 
delayed or unpredictable response to a dose of levodopa. Complete dose failure also may occur.

The dopamine antagonist metoclopramide is effective and widely used to treat gastroparesis but is contraindicated for PD patients because it crosses the blood-brain barrier and blocks dopaminergic function in the brain. Domperidone also is dopamine antagonist but does not cross the blood-brain barrier, rendering it acceptable for use in PD. Domperidone not only improves gastroparesis in PD but also may increase the bioavailability of levodopa [86, 87]. However, it is not approved for use in the USA. Concern has been voiced regarding the potential cardiotoxicity of domperidone [88], but others believe this risk is ill defined and should not prevent judicious use of the drug [89]. The 5- $\mathrm{HT}_{4}$ agonist drugs, mosapride and prucalopride, are effective in reducing gastric emptying time but have undergone only minimal evaluation in individuals with PD; of these, only prucalopride is approved for use in the USA $[90,91]$. Botulinum toxin injection into the pyloric sphincter has been reported in several small studies to improve gastric emptying in patients with $\mathrm{PD}$, but more extensive evaluation still is needed $[92,93]$. The ghrelin receptor agonist relamorelin currently is undergoing clinical trials and has shown efficacy in improving both gastric emptying and symptoms of gastroparesis in patients with diabetes, but it has not been tested for this indication in patients with PD $[94,95]$.

\section{Small Intestinal Dysmotility}

Small intestinal function has not been thoroughly evaluated in the setting of PD, but in 1996, a small study involving 15 patients and 15 healthy controls demonstrated slowed orocecal transit time and reduced absorption of mannitol but normal absorption of lactulose in PD subjects, indicative of decreased nonmediated uptake across the enteric brush border membrane [96]. More recently, using SPECT fused with CT imaging to visualize a small technetium capsule as it transited the gut, slowed small intestinal transit in 10 PD patients was documented [97]. Small intestinal bacterial overgrowth (SIBO) has been recognized in the setting of $\mathrm{PD}$ and appears to be present in 25 to $55 \%$ of patients with PD, compared with 10 to $20 \%$ of control subjects [98-100]; however, spontaneous changes between positive and negative SIBO status can occur [101], perhaps obfuscating the significance of these numbers. PD patients with SIBO may experience GI symptoms; they also may experience increased motor fluctuations and increased off time. Reduced quality of life, but not weight loss, has been associated with SIBO in the setting of PD [102]. Treatment with rifaximin results in improvement in function, but the relapse rate by 6 months is over $40 \%$ [98]. A recent report that gut bacteria within the upper small intestine may reduce levodopa absorption by converting levodopa to dopamine via bacterial tyrosine decarboxylases may have important clinical implications with regard to levodopa efficacy in some individuals with PD [103].

\section{Bowel Dysfunction}

There are two aspects of bowel dysfunction that may occur in PD - decreased bowel movement frequency and difficulty with the act of defecation itself. Decreased frequency, or constipation, is the better recognized of the two, but defecatory dysfunction may be just as common and both may impact quality of life for the PD patient very significantly.

The reported prevalence of decreased bowel movement frequency in PD varies from 20 to $77 \%$ [104] with a median constipation prevalence of 40 to $50 \%$ [105]. The physiological basis of constipation in PD is slowed transit of fecal material through the colon, which is evident in up to $80 \%$ of PD patients [106]. Although constipation may develop at any time during the course of PD, it also may precede the appearance of PD motor features by up to two decades [107], its presence is associated with a sustained increased risk of developing PD [108, 109], and it now is considered one of the markers of prodromal PD [110, 111]. Sigmoid volvulus is a potentially under-recognized serious complication of constipation in PD $[112,113]$.

Treatment of constipation in PD largely parallels the treatment of idiopathic constipation (Fig. 1). Increased dietary fiber and fluid intake are the recommended first steps, often in conjunction with stool softeners. With recognition of the apparent changes in the gut microbiome in PD, interest in the possible effectiveness of probiotics in the treatment of constipation has surfaced, and the effectiveness of probiotics in improving constipation in PD patients has been demonstrated $[114,115]$. However, a note of caution also has been voiced in that available probiotics are not tailored to the PD gut and that, given the possibility that alterations in the gut microbiome may play a role in the development of PD itself, the risk profile of probiotics in PD warrants further investigation [114]. Osmotic laxatives, primarily polyethylene glycol (macrogol), but also lactulose and sorbitol, are widely used when dietary measures are insufficient. An ever-growing stable of prokinetic drugs has been developed with the goal of improving constipation by accelerating colonic motility. Although earlier, less selective $5-\mathrm{HT}_{4}$ agonists, such as cisapride and tegaserod, were withdrawn from use because of cardiotoxicity, the more highly selective prucalopride is now available and has been reported to be effective in a small study of patients with PD $[116,117]$. Intestinal secretagogues, such as the CIC-2 chloride channel activator lubiprostone and the guanylate cyclase- $\mathrm{C}$ agonist linaclotide, also have demonstrated efficacy in improving constipation in small studies of PD patients [116, 118]. Another guanylate cyclase-C agonist, plecanatide, is available but has not been studied specifically in PD patients. Nizatidine, a histamine $\mathrm{H}_{2}$ receptor agonist, also was reported to improve constipation in individuals with a prolonged colon transit time, but not in those with a normal transit time, in an open-label pilot study involving $20 \mathrm{PD}$ patients [119]. The ghrelin agonist relamorelin was evaluated 


\section{Management of Constipation in Parkinson's Disease}

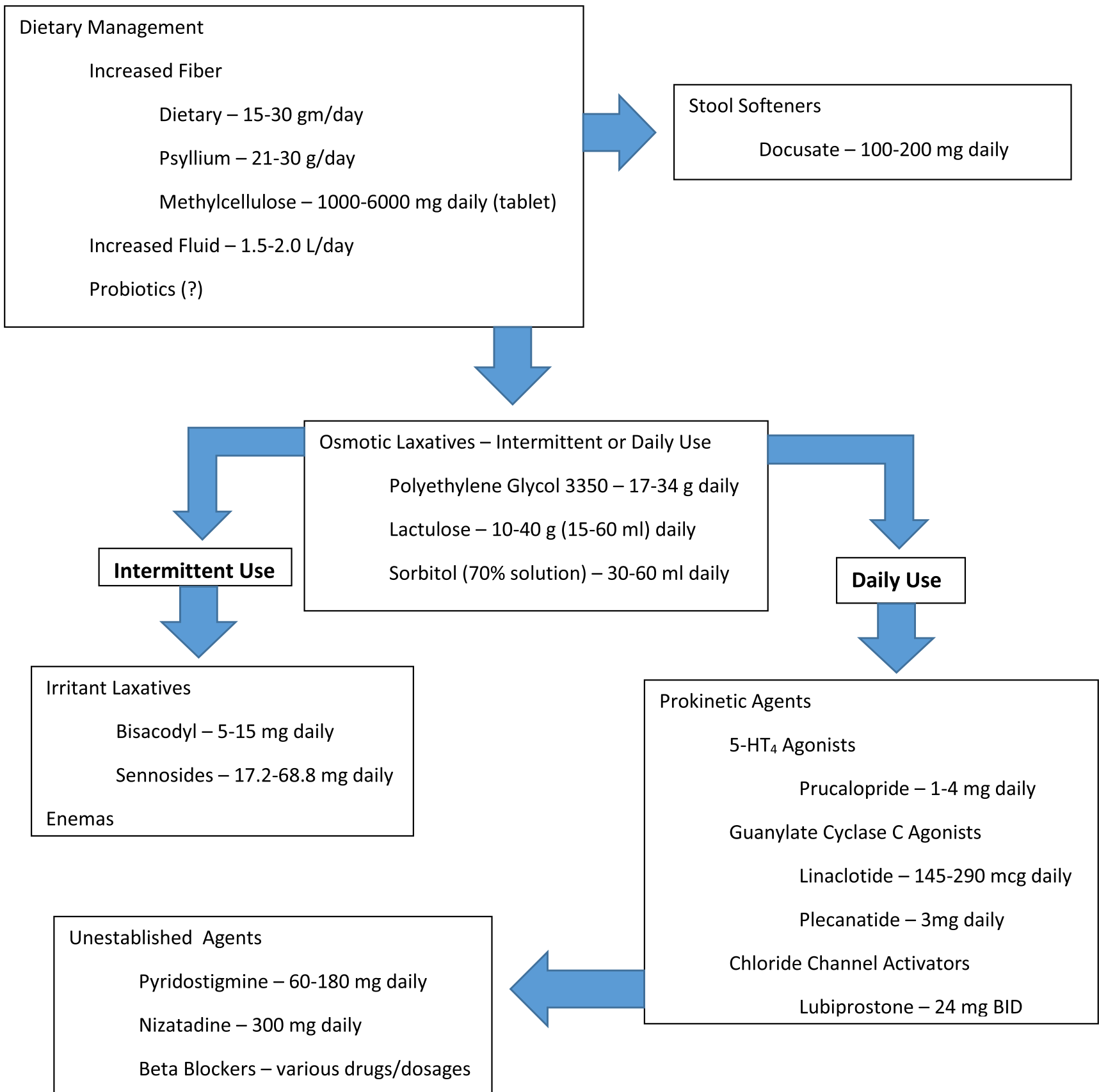

Fig. 1 Management of constipation in Parkinson's disease.

for the treatment of constipation in PD patients, but recruitment difficulties did not permit a definitive conclusion regarding its effectiveness [120]. An anecdotal report proposed the effectiveness of the cholinomimetic pyridostigmine, but no formal studies have been reported [121]. Beta-blockers may reduce the risk of constipation in $\mathrm{PD}$, but no prospective study has been reported [122]. Nonpharmacologic modalities, such as functional magnetic stimulation, have been reported to be effective in reducing colon transit time in individuals with PD
[123], as has abdominal massage [124]. Improvement in constipation following subthalamic deep brain stimulation surgery has been documented [77]. Fecal microbiome transplantation for the treatment of constipation in PD is a source of interest and promise, but definitive studies are still lacking [114]. Enemas may be used as needed; surgical intervention in the form of colectomy is a last resort and rarely necessary.

Anorectal or defecatory dysfunction is characterized by increased straining, painful defecation, and incomplete 
emptying. Symptoms of defecatory dysfunction may be present in 61 to $67 \%$ of individuals with PD $[50,125]$ and may be evident in both early and advanced PD [126]. In one study, symptoms of defecatory dysfunction were, by patient report, present prior to the appearance of classic motor symptoms in almost $60 \%$ of individuals [125].

In individuals with defecatory dysfunction, stool softeners may make stool easier to expel but laxatives typically are not helpful and may even make patients more uncomfortable. Formal studies of potential treatment modalities have been rare. In an open study involving 19 patients with PD, treatment with levodopa significantly reduced the amplitude of paradoxical sphincter contraction during defecation and reduced postdefecation residuals [127]. Apomorphine injections improved defecatory function in some individuals in another small study, but more formal and extensive testing has not been pursued [128]. Botulinum toxin injections into the external anal sphincter and puborectalis muscles have been administered with good results in relieving defecatory dysfunction in several relatively small studies of PD patients [93, 129]. Biofeedback has not been formally studied in patients with PD. STN-DBS produced improvement in anal squeeze pressure, but not in anorectal dyssynergia, in a study of $16 \mathrm{PD}$ patients [130].

\section{Urinary Dysfunction}

Although reports estimating the prevalence of bladder dysfunction in PD vary widely, ranging between 27 and $86 \%$, there certainly is a consensus that it occurs frequently and that it can have a significant effect on quality of life for affected individuals [131-136]. In a survey of 545 PD patients using the NMSQuest, the most frequently reported nonmotor symptoms were urinary urgency in 56\% and nocturia in 62\% [137]. Although the development of urinary symptoms tends to correlate with disease progression, in approximately $4 \%$ of persons, urinary symptoms may be the initial feature of PD [138].

The brainstem micturition centers in the pons are influenced by the basal ganglia, with the net effect of the basal ganglia on the micturition reflex being inhibitory [139]. In PD, neurodegenerative changes within the basal ganglia, with a consequent decrease in dopaminergic function, result in disinhibition of the micturition reflex, which, in turn, results in detrusor overactivity [140]. Detrusor overactivity is the most common urinary problem in PD and is characterized by urinary frequency, urgency, and nocturia, with a sensation of bladder fullness and an urge to void before appropriate bladder filling has occurred. Detrusor hyperreflexia is present in 45 to $100 \%$ of individuals with PD, although not all are symptomatic $[141,142]$. Urodynamic testing demonstrates detrusor overactivity in 67 to $100 \%$ of PD patients with urinary symptoms $[143,144]$. However, bladder overactivity is not the only urinary difficulty that may be experienced by individuals with PD. Urinary hesitancy and reduced urinary stream secondary to impaired bladder emptying may account for up to $27 \%$ of urinary symptoms in PD [145]. Detrusor underactivity, which if symptomatic is characterized by decreased sensation during filling and incomplete emptying without actual obstruction of urine outflow, may be present in over $40 \%$ of individuals with PD who are experiencing symptoms of urinary dysfunction and may actually coexist with detrusor overactivity [144]. Sphincter bradykinesia, with delayed relaxation of the urethral sphincters and pelvic muscles upon attempted voiding, may be present in 11 to $42 \%$ of symptomatic patients and produce a picture of obstructed flow [146, 147]. It also is important to remember that in men with $\mathrm{PD}$, other independent processes producing obstructive bladder emptying, such as prostatic hypertrophy, can coexist with the detrusor hyperreflexia of PD itself and produce a complicated clinical picture that requires urodynamic testing for clarification and appropriate treatment decisions [148].

Both nonpharmacologic and pharmacologic approaches are available for the management of overactive bladder symptoms, although specific testing in patients with PD has been limited. Nonpharmacologic strategies include basic recommendations such as reducing caffeine and alcohol intake, but also more sophisticated approaches such as instruction in urge suppression and distraction techniques, establishment of personalized voiding schedules, and performance of pelvic floor exercises [149, 150]. Anticholinergic drugs acting on muscarinic receptors in the bladder have been the primary pharmacologic approach to the treatment of overactive bladder symptoms. They are effective, but older, nonselective muscarinic anticholinergic drugs, such as oxybutynin and tolterodine, are ideally avoided in PD patients because their anticholinergic activity within the CNS may compromise cognitive function. Newer, more selective, anticholinergic drugs have been developed that may circumvent this problem. Darifenacin does not cross the blood-brain barrier and is selective for $\mathrm{M} 3$ receptors, which are primarily located in the bladder. It has been shown to spare cognitive function in both younger and older individuals but has not been specifically tested in PD patients [151, 152]. Solifenacin also is a selective M3 receptor antagonist and has been studied in a pilot clinical trial in patients with PD and found to be of some benefit in the open-label phase of the study [153]. Trospium, yet another newer anticholinergic drug, does not cross the blood-brain barrier but has not been specifically tested in PD patients. Drugs with other mechanisms of action are now available for treating overactive bladder symptoms and have been evaluated in PD patients. Mirabegron, a $\beta 3$ adrenergic agonist, has demonstrated efficacy in reducing overactive bladder symptoms in several small, nonblinded studies in PD patients [135, 154]. However, mirabegron does have the capability of inducing orthostatic hypotension, so care is needed in its use. Drugs 
employed to treat motor features of PD also may be useful in alleviating overactive bladder symptoms. The adenosine A2A receptor antagonist istradefylline, which was recently approved in the USA for use in treating the motor symptoms of $\mathrm{PD}$, has been reported to also reduce lower urinary tract symptoms [132], and bedtime administration of extendedrelease levodopa may improve nocturia in PD patients [155]. Botulinum toxin injections into the detrusor muscle, performed under cystoscopic guidance, have been employed successfully in the treatment of detrusor overactivity in patients with PD, with success rates of 80 to $100 \%$ [134, 156, 157]. However, an elevated postvoid residual prior to injection increases the risk of both treatment failure and postoperative urinary retention severe enough to require intermittent selfcatheterization [134]. Neuromodulation in the form of both percutaneous and transdermal tibial nerve stimulations has been used successfully in ameliorating overactive bladder symptoms, but experience specifically in individuals with PD currently is minimal [158]. Improvement in lower urinary tract symptoms in PD patients has been documented following deep brain stimulation surgery targeting the subthalamic nucleus $[159,160]$. In one study, improvement following DBS was more apparent in females than in males; the reason for this is unclear [160].

Treatment of obstructive urinary symptoms in patients with PD often is unsatisfactory. If prostatic hypertrophy is discovered, alpha-adrenergic antagonists, such as tamsulosin, terazosin, and doxazosin, or 5-alpha reductase inhibitors, such as dutasteride or finasteride, can be utilized. However, care must be taken because these drugs also can worsen orthostatic hypotension. Urethral sphincter bradykinesia, which has been described in PD, may respond to dopaminergic medications [161]. Botulinum toxin injections into the urethral sphincter have been administered for the treatment of detrusor underactivity, nonrelaxing urethral sphincter, and urinary retention for other reasons, but not specifically in PD patients [162]. In patients with PD and detrusor underactivity, intermittent catheterization may be the most effective treatment, although individuals with advanced $\mathrm{PD}$ may require assistance in performing the catheterization.

\section{Sexual Dysfunction}

There has been a relative paucity of research regarding sexual dysfunction in PD, which likely reflects a reluctance on the part of both patients and physicians to address and discuss this sensitive issue [163]. According to a study involving 60 PD patients and an equal number of controls, sexual dysfunction is present in $82 \%$ of patients with $\mathrm{PD}$, compared with $48 \%$ of controls [164]. In another study, decreased sexual frequency was reported by $80 \%$ of men and $79 \%$ of women; decreased sexual interest, however, was noted by $71 \%$ of women but only $44 \%$ of men [165]. Erectile dysfunction and impairment of ejaculation develop in up to $79 \%$ of men with PD [166]. More recently, erectile dysfunction was present in $70 \%$ of a group of 40 male patients compared with 25 control subjects; other aspects of sexual function, such as orgasmic function, sexual desire, intercourse satisfaction, and overall satisfaction, also were impaired, particularly in individuals over age 55 [167]. Sexual dysfunction is more likely to become evident in PD patients with depression [164] and with the postural instability-gait disorder phenotype [168]. Acquired premature ejaculation also may occur in the setting of PD [169]. In contrast to the studies detailed above, a study in which $121 \mathrm{PD}$ patients were compared with 123 non-PD control subjects did not find any differences between the two groups in four different sexual function scales [170]. Furthermore, a systematic review and meta-analysis covering 11 studies published between 1992 and 2018 reported that PD was associated with an increased risk of sexual dysfunction in men but not in women [171]. These studies illustrate the need for additional research into sexual dysfunction in PD.

Penile erection and detumescence are the culmination of a complex neurovascular process under the control of both the central and the peripheral autonomic and the peripheral somatic nervous systems, with further modulation by a variety of contracting and relaxing mediators [172]. This complexity provides a plethora of potential treatment targets for erectile dysfunction, but currently approved treatment approaches focus on drugs that inhibit cGMP-specific phosphodiesterase type 5. Several such inhibitors are available, including sildenafil, tadalafil, vardenafil, and avanafil. The safety and effectiveness of sildenafil in improving erectile functioning has been documented in several studies of men with PD [173-175]. However, in a double-blind, placebo-controlled, cross-over study, sildenafil did not improve quality of life despite improving erectile functioning [175]. Orthostatic hypotension is a risk, particularly for individuals with $\mathrm{PD}$, with all of these agents. Testosterone deficiency has been reported in men with PD; in one study, it was present in 35\% of participants [176] but the efficacy and long-term safety of testosterone replacement for the treatment of sexual dysfunction is unproven. For individuals in whom sildenafil or similar drugs have been ineffective or not tolerated, other treatment approaches are available, although they have not been specifically evaluated in patients with PD. Intracavernosal injections of alprostadil and moxisylyte are effective, but the injections may be painful and may trigger formation of fibrotic nodules within the corpora. Vacuum devices, used in conjunction with constrictor bands, also are effective in inducing penile erection, but patient acceptance of the devices is low. The possibility that drugs affecting dopaminergic function, such as apomorphine or dopamine $\mathrm{D}_{4}$ receptor agonists, might be useful in treating erectile dysfunction has been investigated [177]. No studies of pharmacologic treatment of sexual dysfunction 
in women with PD have been reported. Sex therapy can be important in the management of sexual dysfunction in individuals with $\mathrm{PD}$, and it is important for treating physicians that they do not shy away from initiating discussion regarding sexual dysfunction with their PD patients [178].

Hypersexual behavior is a well-known impulse control complication of dopamine agonist therapy, which will not be addressed here. However, sexual preoccupation behaviors, including hypersexuality and compulsive sexual behavior, have been described as part of PD itself [179, 180]. Restless genital syndrome, characterized by pain, numbness, vibration, or burning sensations involving the vagina, penis, perineum, pelvis, or proximal lower limbs, also has been reported in PD [181]. This may occur as a wearing-off phenomenon and respond to subcutaneous apomorphine injection [182].

\section{Thermoregulatory Dysfunction}

Thermoregulatory dysfunction has received relatively sparse attention as an aspect of autonomic dysfunction in PD, but actually, it is quite common. The reported prevalence of sweating disturbances in PD varies widely, but estimates typically fall within the range of 30 to $70 \%[183,184]$. It may occur at any time during the course of $\mathrm{PD}$ and may precede the development of the classic motor features by more than 10 years [185].

Thermoregulatory dysfunction in PD may be the consequence of abnormalities both in the central nervous system and in the peripheral nervous system. The existence of Lewy bodies within the hypothalamus [186] and alpha-synuclein accumulation in preganglionic neurons in the intermediolateral cell column of the spinal cord and in the sympathetic ganglia supports the presence of a central component [187, 188], as do reports of hyperhidrosis being triggered by subthalamic deep brain stimulation [189]. Conversely, small fiber peripheral neuropathy, with reduced innervation of blood vessels, sweat glands, and erector pili muscles, has been reported by multiple investigators in patients with $\mathrm{PD}$, although its etiology remains uncertain and both vitamin $\mathrm{B}_{12}$ deficiency and levodopa toxicity have been implicated [184].

Both heat and cold intolerance may be experienced by persons with PD. A sensation of coldness involving the distal legs may be associated with pain and difficulty walking [190]. Prolonged vasoconstriction, produced by peripheral autonomic impairment, along with central autonomic dysfunction may be responsible [191]. Burning sensations, most frequently involving the trunk and proximal extremities, also may develop in PD [192].

Both hyperhidrosis and hypohidrosis may become evident in individuals with PD. Excessive sweating may be generalized or asymmetric and, when asymmetric, is more likely to be on the side of greater motor involvement $[184,193]$. A pattern of increased sweating involving the head, neck, and upper trunk may represent a compensatory mechanism for reduced sweating over the distal extremities, particularly the legs [194-196]. Hyperhidrosis in PD often is episodic and may occur unpredictably, sometimes at night. More often, however, it is related to motor function, occurring either as an off phenomenon or during episodes of severe dyskinesia [184, 197, 198]. Hyperhidrosis may be associated with a dysautonomiadominant subtype of PD [199]. Hypohidrosis typically is less bothersome than hyperhidrosis to affected individuals, but it leaves them at increased risk of heat intolerance.

Acute hyperthermia may develop in the setting of PD, most frequently after the intentional or inadvertent precipitous discontinuation of prescribed levodopa [200, 201], but development of hyperthermia following discontinuation of fava beans (which contain levodopa) also has been described [202]. It also may occur as a consequence of impaired levodopa absorption following initiation of enteral feedings [203, 204]. Development in the midst of a severe off episode also has been described with a fatal outcome [205].

Little has been published regarding the treatment of thermoregulatory dysfunction in PD. Avoiding exposure to temperature extremes is sensible. Anticholinergic medications should be avoided by persons with impaired sweating. Excessive sweating, if it occurs as a wearing-off phenomenon or during episodes of severe dyskinesia, may be amenable to treatment by judicious adjustment of antiparkinson medication, but for frequent, unpredictable episodes that are not correlated with the timing of medication administration, no medication or other treatment modalities have been consistently effective. Botulinum toxin injections could be considered for the control of axillary hyperhidrosis but would not be useful for the more generalized hyperhidrosis characteristic of PD. Deep brain stimulation surgery targeting the subthalamic nucleus has been reported to reduce paroxysmal drenching sweats, but it has not been used specifically for this problem [206, 207].

\section{Conclusion}

Autonomic dysfunction is a frequent, often significant, and sometimes devastating feature of PD. Although most often associated with advanced PD, autonomic dysfunction may appear early in the course of the disease and may even precede the development of the classic motor features, sometimes by years. Autonomic dysfunction can severely impact quality of life for individuals with PD, so it is vitally important that clinicians are aware that effective treatment is available for many, though not all, aspects of autonomic dysfunction in PD. It also is important to recognize that patients often may not spontaneously mention that they are experiencing symptoms of autonomic dysfunction, either because of a failure to recognize that the symptoms are part of $\mathrm{PD}$ or, in some 
instances, because of embarrassment. Therefore, it is incumbent upon physicians to inquire regularly about the presence of autonomic symptoms during clinic visits, so that appropriate treatment can be initiated.

Required Author Forms Disclosure forms provided by the authors are available with the online version of this article.

\section{References}

1. Siddiqui MF, Rast S, Lynn MJ, Auchus AP, Pfeiffer RF. Autonomic dysfunction in Parkinson's disease: a comprehensive symptom survey. Parkinsonism Relat Disord 2002;8(4):277-284.

2. Khoo TK, Yarnall AJ, Duncan GW, et al. The spectrum of nonmotor symptoms in early Parkinson disease. Neurology 2013;80(3):276-281.

3. Stanković I, Petrović I, Pekmezović T, et al. Longitudinal assessment of autonomic dysfunction in early Parkinson's disease. Parkinsonism Relat Disord 2019;66:74-79.

4. De Pablo-Fernandez E, Tur C, Revesz T, Lees AJ, Holton JL, Warner TT. Association of autonomic dysfunction with disease progression and survival in Parkinson disease. JAMA Neurol 2017;74(8):970-976.

5. Tsiouris KM, Konitsiotis S, Koutsouris DD, Fotiadis DI. Prognostic factors of rapid symptoms progression in patients with newly diagnosed Parkinson's disease. Artif Intell Med 2020;103: 101807.

6. Djaldetti R, Lev N, Melamed E. Lesions outside the CNS in Parkinson's disease. Mov Disord 2009;24(6):793-800.

7. Evatt ML, Chaudhuri KR, Chou KL, et al. Dysautonomia rating scales in Parkinson's disease: sialorrhea, dysphagia, and constipation - critique and recommendations by Movement Disorders Task Force on Rating Scales for Parkinson's Disease. Mov Disord 2009;24(5):635-646.

8. Pavy-Le Traon A, Amarenco G, Duerr S, et al. The Movement Disorders Task Force review of dysautonomia rating scales in Parkinson's disease with regard to symptoms of orthostatic hypotension. Mov Disord 2011;26(11):1985-1992.

9. Pavy-Le Traon A, Cotterill N, Amarenco G, et al. Clinical rating scales for urinary symptoms in Parkinson's disease: critique and recommendations. Mov Disord Clin Pract 2018;5(5):479-491.

10. Driver-Dunckley ED, Zhang N, Shill HA, et al. Movement Disorders Society's Unified Parkinson's Disease Rating Scale and nonmotor scales in patients with Parkinson's disease. Innov Clin Neurosci 2019;16(9-10):27-29.

11. Tanner CM, Kieburtz K, Galpern W, et al. Facilitating clinical research: the National Institute of Neurological Disorders and Stroke (NINDS) Parkinson's Disease Common Data Elements project. Parkinsonism Relat Disord 2012;18S2:S10-S11.

12. Goldstein DS. Dysautonomia in Parkinson's disease: neurocardiological abnormalities. Lancet Neurol 2003;2(11): 669-676.

13. Amino T, Orimo S, Itoh Y, Takahashi A, Uchihara T, Mizusawa H. Profound cardiac sympathetic denervation occurs in Parkinson disease. Brain Pathol 2005;15(1):29-34.

14. Rascol O, Schelosky L. ${ }^{123}$ I-Metaiodobenzylguanidine scintigraphy in Parkinson's disease and related disorders. Mov Disord 2009;24(Suppl 2):S732-S741.
15. Goldstein DS, Holmes C, Bentho O, et al. Biomarkers to detect central dopamine deficiency and distinguish Parkinson disease from multiple system atrophy. Parkinsonism Relat Disord 2008;14(8):600-607.

16. Orimo S, Suzuki M, Inaba A, Mizusawa H. ${ }^{123}$ I-MIBG myocardial scintigraphy for differentiating Parkinson's disease from other neurodegenerative parkinsonism: a systematic review and metaanalysis. Parkinsonism Relat Disord 2012;18(5):494-500.

17. Haensch CA, Lerch H, Jörg J, Isenmann S. Cardiac denervation occurs independent of orthostatic hypotension and impaired heart rate variability in Parkinson's disease. Parkinsonism Relat Disord 2009;15(2):134-137.

18. Katagiri A, Asahina M, Araki N, et al. Myocardial (123)I-MIBG uptake and cardiovascular autonomic function in Parkinson's disease. Parkinsons Dis 2015;2015:805351.

19. Freeman R, Wieling W, Axelrod FB, et al. Consensus statement on the definition of orthostatic hypotension, neutrally mediated syncope and the postural tachycardia syndrome. Clin Auton Res 2011;21(2):69-72.

20. Cutsforth-Gregory JK, Low PA. Neurogenic orthostatic hypotension in Parkinson disease: a primer. Neurol Ther 2019;8:307-324.

21. Palma JA, Kaufmann H. Orthostatic hypotension in Parkinson disease. Clin Geriatr Med 2020;36:53-67.

22. Shaw BH, Garland EM, Black BK, et al. Optimal diagnostic thresholds for diagnosis of orthostatic hypotension with a "sit-tostand test." J Hypertens 2017;35(5):1019-1025.

23. Gibbons CH, Freeman R. Clinical implications of delayed orthostatic hypotension. Neurology 2015;85:1362-1367.

24. Gibbons CH, Schmidt P, Biaggioni I, et al. The recommendations of a consensus panel for the screening, diagnosis, and treatment of neurogenic orthostatic hypotension and associated supine hypertension. J Neurol 2017;264:1567-1582.

25. Velseboer DC, de Haan RJ, Wieling W, Goldstein DS, de Bie RMA. Prevalence of orthostatic hypotension in Parkinson's disease: a systematic review and meta-analysis. Parkinsonism Relat Disord 2011;17(10):724-729.

26. Kim JS, Lee SH, Oh YS, et al. Cardiovascular autonomic dysfunction in mild and advanced Parkinson's disease. J Mov Disord 2016;9(2):97-103

27. Strano S, Fanciulli A, Rizzo M, et al. Cardiovascular dysfunction in untreated Parkinson's disease: a multi-modality assessment. J Neurol Sci 2016;370:251-255.

28. Senard JM, Raï S, Lapeyre-Mestre M, et al. Prevalence of orthostatic hypotension in Parkinson's disease. J Neurol Neurosurg Psychiatry 1997;63(5):584-589.

29. Merola A, Romagnolo A, Rosso M, et al. Orthostatic hypotension in Parkinson's disease: does it matter if asymptomatic? Parkinsonism Relat Disord 2016;33:65-71.

30. Quarracino C, Otero-Losada M, Capani F, Pérez-Lloret S. Prevalence and factors related to orthostatic syndromes in recently diagnosed, drug naïve patients with Parkinson disease. Clin Auton Res 2019; https://doi.org/10.1007/s10286-019-00652-6

31. Rascol O, Perez-Lloret S, Damier P, et al. Falls in ambulatory nondemented patients with Parkinson's disease. J Neural Transm (Vienna) 2015;122(10):1447-1455.

32. Espay AJ, LeWitt PA, Hauser RA, Merola A, Masellis M, Lang AE. Neurogenic orthostatic hypotension and supine hypertension in Parkinson's disease and related synucleinopathies: prioritisation of treatment targets. Lancet Neurol 2016;15(9):954-966.

33. Rowell LB, Detry JM, Blackmon JR, Wyss C. Importance of the splanchnic vascular bed in human blood pressure regulation. $\mathrm{J}$ Appl Physiol 1972;32(2):213-220.

34. Figueroa JJ, Singer W, Sandroni P, et al. Effects of patientcontrolled abdominal compression on standing systolic blood pressure in adults with orthostatic hypotension. Arch Phys Med Rehabil 2015;96(3):505-510. 
35. Low PA, Tomalia VA. Orthostatic hypotension: mechanisms, causes, management. J Clin Neurol 2015;11(3):220-226.

36. Hussain RM, McIntosh SJ, Lawson J, Kenny RA. Fludrocortisone in the treatment of hypotensive disorders in the elderly. Heart 1996;76(6):507-509.

37. Chen JJ, Han Y, Tang J, Portillo I, Hauser RA, Dashtipour K. Standing and supine blood pressure outcomes associated with droxidopa and midodrine in patients with neurogenic orthostatic hypotension: a Bayesian meta-analysis and mixed treatment comparison of randomized trials. Ann Pharmacother 2018;52(12): 1182-1194.

38. McClellan KJ, Wiseman LR, Wilde MI. Midodrine. A review of its therapeutic use in the management of orthostatic hypotension. Drugs Aging 1998;12(1):76-86.

39. Kaufmann H, Norcliffe-Kaufmann L, Hewitt LA, Rowse GJ, White WB. Effects of the novel norepinephrine prodrug, droxidopa, on ambulatory blood pressure in patients with neurogenic orthostatic hypotension. J Am Soc Hypertens 2016;10(10): 819-826.

40. Kaufmann H. Droxidopa for symptomatic neurogenic orthostatic hypotension: what can we learn? Clin Auton Res 2017;27(Suppl 1): $1-3$.

41. McDonell KE, Shibao CA, Biaggioni I, Hartman A, Robertson D, Claasen DO. Cognitive and behavioral changes in patients treated with droxidopa for neurogenic orthostatic hypotension: a retrospective review. Cogn Behav Neurol 2019;32(3):179-184.

42. Sharabi Y, Goldstein DS. Mechanisms of orthostatic hypotension and supine hypertension in Parkinson's disease. J Neurol Sci 2011;310(1-2):123-128.

43. Cicconetti P, Ciotti V, Monteforte G, et al. Circadian blood pressure pattern and cognitive function in newly diagnosed older hypertensives. Blood Press 2003;12(3):168-174

44. Routledge F, McFetridge-Durdle J. Nondipping blood pressure patterns among individuals with essential hypertension: a review of the literature. Eur J Cardiovasc Nurs 2007;6(1):9-26.

45. Fanciulli A, Jordan J, Biaggioni I, et al. Consensus statement on the definition of neurogenic supine hypertension in cardiovascular autonomic failure by the American Autonomic Society (AAS) and the European Federation of Autonomic Societies (EFAS). Clin Auton Res 2018;28(4):355-362.

46. Fanciulli A, Göbel G, Ndayisaba JP, et al. Supine hypertension in Parkinson's disease and multiple system atrophy. Clin Auton Res 2016;26(2):97-105.

47. Umehara T, Matsuno H, Toyoda C, Oka H. Clinical characteristics of supine hypertension in de novo Parkinson disease. Clin Auton Res 2016;26(1):15-21.

48. Biaggioni I. Orthostatic hypotension in the hypertensive patient. Am J Hypertens 2018;31(12):1255-1259.

49. Gamboa A, Shibao C, Diedrich A, et al. Excessive nitric oxide function and blood pressure regulation in patients with autonomic failure. Hypertension 2008;51:1531-1536.

50. Edwards LL, Pfeiffer RF, Quigley EM, Hofman R, Balluff M. Gastrointestinal symptoms in Parkinson's disease. Mov Disord 1991;6(2):151-156.

51. Verbaan D, Marinus J, Visser M, van Rooden SM, Stiggelbout $\mathrm{AM}$, van Hilten JJ. Patient-reported autonomic symptoms in Parkinson disease. Neurology 2007;69(4):333-341.

52. van Wamelen DJ, Leta V, Johnson J, et al. Drooling in Parkinson's disease: prevalence and progression from the Nonmotor International Longitudinal Study. Dysphagia 2020; https:// doi.org/10.1007/s00455-020-10102-5.

53. Karakoc M, Yon MI, Cakmakli GY, et al. Pathophysiology underlying drooling in Parkinson's disease: oropharyngeal bradykinesia. Neurol Sci 2016;37(12):1987-1991.
54. Hyson HC, Johnson AM, Jog MS. Sublingual atropine for sialorrhea secondary to parkinsonism: a pilot study. Mov Disord 2002;17(6):1318-1320.

55. Isaacson SH, Ondo W, Jackson CE, et al. Safety and efficacy of rimabotulinumtoxin $\mathrm{B}$ for treatment of sialorrhea in adults. A randomized clinical trial. JAMA Neurol 2020; https://doi.org/10. 1001/jamaneurol.2019.4565

56. Jost WH, Friedman A, Michel O, et al. Long-term incobotulinumtoxinA treatment for chronic sialorrhea: efficacy and safety over 64 weeks. Parkinsonism Relat Disord 2020;70: 23-30.

57. Narayanaswami P, Geisbush T, Tarulli A, et al. Drooling in Parkinson's disease: a randomized controlled trial of incobotulinum toxin A and a meta-analysis of botulinum toxins. Parkinsonism Relat Disord 2016;30:73-77.

58. Ondo WG, Hunter C, Moore W. A double-blind placebo-controlled trial of botulinum toxin B for sialorrhea in Parkinson's disease. Neurology 2004;62(1):37-40.

59. Pfeiffer RF. Gastrointestinal dysfunction in Parkinson's disease. Parkinsonism Relat Disord 2011;17(1):10-15.

60. Kalf JG, de Swart BJM, Bloem BR, Munneke M. Prevalence of oropharyngeal dysphagia in Parkinson's disease: a meta-analysis. Parkinsonism Relat Disord 2012;18:311-315.

61. Jones CA, Ciucci MR. Multimodal swallowing evaluation with high-resolution manometry reveals subtle swallowing changes in early and mid-stage Parkinson disease. J Parkinsons Dis 2016;6(1):197-208.

62. Paul BS, Singh T, Paul G, et al. Prevalence of malnutrition in Parkinson's disease and correlation with gastrointestinal symptoms. Ann Indian Acad Neurol 2019;22(4):447-452.

63. Fabbri M, Coelho M, Abreu D, et al. Dysphagia predicts poor outcome in late-stage Parkinson's disease. Parkinsonism Relat Disord 2019;64:73-81.

64. Buhmann C, Bihler M, Emich K, et al. Pill swallowing in Parkinson's disease: a prospective study based on flexible endoscopic evaluation of swallowing. Parkinsonism Relat Disord 2019;62:51-56.

65. Pfeiffer RF. Gastrointestinal dysfunction in Parkinson's disease. In: Pfeiffer RF, Wszolek ZK, Ebadi M, eds. Parkinson's disease. 2. Boca Raton: CRC Press; 2013: 309-326.

66. Gross RD, Atwood CW Jr, Ross SB, Eichhorn KA, Olszewski JW, Doyle PJ. The coordination of breathing and swallowing in Parkinson's disease. Dysphagia 2008;23(2):136-145.

67. Byrne KG, Pfeiffer R, Quigley EM. Gastrointestinal dysfunction in Parkinson's disease. A report of clinical experience at a single center. J Clin Gastroenterol 1994;19(1):11-16.

68. Suttrup I, Warnecke T. Dysphagia in Parkinson's disease. Dysphagia 2016;31(1):24-32.

69. Curtis JA, Troche MS. Handheld cough testing: a novel tool for cough assessment and dysphagia screening. Dysphagia 2020; https://doi.org/10.1007/s00455-020-10097-z.

70. Menezes C, Melo A. Does levodopa improve swallowing dysfunction in Parkinson's disease patients? J Clin Pharm Ther 2009;34(6):673-676.

71. Warnecke T, Suttrup I, Schröder JB, et al. Levodopa responsiveness of dysphagia in advanced Parkinson's disease and reliability testing of the FEES-levodopa-test. Parkinsonism Relat Disord 2016;28:100-106.

72. Hirano M, Isono C, Fukuda K, Ueno S, Nakamura Y, Kusunoki S. Effects of the rotigotine transdermal patch versus oral levodopa on swallowing in patients with Parkinson's disease. J Neurol Sci 2019;404:5-10.

73. Troche MS, Okun MS, Rosenbek JC, et al. Aspiration and swallowing in Parkinson disease and rehabilitation with EMST: a randomized trial. Neurology 2010:75(21):1912-1919. 
74. Byeon H. Effect of simultaneous application of postural techniques and expiratory muscle strength training on the enhancement of the swallowing function of patients with dysphagia caused by Parkinson's disease. J Phys Ther Sci 2016;28(6):1840-1843.

75. Curtis JA, Dakin AE, Troche MS. Respiratory-swallow coordination training and voluntary cough skill training: a single-subject treatment study in a person with Parkinson's disease. J Speech Lang Hear Res 2020;63(2):472-486.

76. Miles A, Jardine M, Johnston F, de Lisle M, Friary P, Allen J. Effect of Lee Silverman Voice Treatment (LSVT-LOUD®) on swallowing and cough in Parkinson's disease: a pilot study. J Neurol Sci 2017;383:180-187.

77. Kawaguchi M, Samura K, Miyagi Y, et al. The effects of chronic subthalamic stimulation on nonmotor symptoms in advanced Parkinson's disease, revealed by an online questionnaire program. Acta Neurochir 2020;162:247-255.

78. Yin Z, Cao Y, Zheng S, et al. Persistent adverse effects following different targets and periods after bilateral deep brain stimulation in patients with Parkinson's disease. J Neurol Sci 2018;393:116127.

79. Khedr EM, Mohamed KO, Soliman RK, Hassan AMM, Rothwell JC. The effect of high-frequency repetitive transcranial magnetic stimulation on advancing Parkinson's disease with dysphagia: double blind randomized clinical trial. Neurorehabil Neural Repair 2019;33(6):442-452.

80. Restivo DA, Palmeri A, Marchese-Ragona R. Botulinum toxin for cricopharyngeal dysfunction in Parkinson's disease. N Engl J Med 2002;346(15):1174-1175.

81. Born LJ, Harned RH, Rikkers LF, Pfeiffer RF, Quigley EM. Cricopharyngeal dysfunction in Parkinson's disease: role in dysphagia and response to myotomy. Mov Disord 1996;11(1):53-58.

82. Pasricha PJ, Parkman HP. Gastroparesis: definitions and diagnosis. Gastroenterol Clin North Am 2015;44(1):1-7.

83. Heetun ZS, Quigley EM. Gastroparesis and Parkinson's disease: a systematic review. Parkinsonism Relat Disord 2012;18(5):433440.

84. Su A, Gandhy R, Barlow C, Triadafilopuolos G. Utility of the wireless motility capsule and lactulose breath testing in the evaluation of patients with Parkinson's disease who present with functional gastrointestinal symptoms. BMJ Open Gastroenterol 2017;4: https://doi.org/10.1136/bmjgast-2017-000132.

85. Tanaka $\mathrm{Y}$, Kato $\mathrm{T}$, Nishida $\mathrm{H}$, et al. Is there a delayed gastric emptying of patients with early-stage, untreated Parkinson's disease? An analysis using the ${ }^{13} \mathrm{C}$-acetate breath test. J Neurol 2011;258(3):421-426.

86. Soykan I, Sarosiek I, Shifflett J, Wooten GF, McCallum RW. Effect of chronic oral domperidone therapy on gastrointestinal symptoms and gastric emptying in patients with Parkinson's disease. Mov Disord 1997;12(6):952-957.

87. Nishikawa N, Nagai M, Tsujii T, Iwaki H, Yabe H, Nomoto M. Coadministration of domperidone increases plasma levodopa concentration in patients with Parkinson disease. Clin Neuropharmacol 2012;35(4):182-184.

88. Leelakanok K, Holcombe A, Schweizer ML. Domperidone and risk of ventricular arrhythmia and cardiac death: a systematic review and meta-analysis. Clin Drug Investig 2016;36(2):97-107.

89. Buffery PJ, Strother RM. Domperidone safety: a mini-review of the science of QT prolongation and clinical implications of recent global regulatory recommendations. N Z Med J 2015;128(1416): 66-74.

90. Asai H, Udaka F, Hirano M, et al. Increased gastric motility during $5-\mathrm{HT}_{4}$ agonist therapy reduces response fluctuations in Parkinson's disease. Parkinsonism Relat Disord 2005;11:499-502.

91. Pinyopornpanish K, Soontornpun A, Kijdamrongthum P, Teeyasoontranon W, Angkurawaranon C, Thongsawat S. The effect of prucalopride on gastric emptying in Parkinson's disease patients, a pilot randomized, open-label study. Digit Syst 2017;1(1):1-6.

92. Gil RA, Hwynn N, Fabian T, Joseph S, Fernandez HH. Botulinum toxin type A for the treatment of gastroparesis in Parkinson's disease patients. Parkinsonism Relat Disord 2011;17(4):285-287.

93. Triadafilopoulos G, Gandhy R, Barlow C. Pilot cohort study of endoscopic botulinum neurotoxin injection in Parkinson's disease. Parkinsonism Relat Disord 2017;44:33-37.

94. Lembo A, Camilleri M, McCallum R, et al. Relamorelin reduces vomiting frequency and severity and accelerates gastric emptying in adults with diabetic gastroparesis. Gastroenterology 2016;151(1):87-96.e6.

95. Camilleri M, McCallum RW, Tack J, Spence SC, Gottesdiener K, Fiedorek FT. Efficacy and safety of relamorelin in diabetics with symptoms of gastroparesis: a randomized, placebo-controlled study. Gastroenterology 2017;153:1240-1250.

96. Davies KN, King D, Billington D, Barrett JA. Intestinal permeability and orocaecal transit time in elderly patients with Parkinson's disease. Postgrad Med J 1996;72:164-167.

97. Dutkiewicz J, Szlufik S, Nieciecki M, et al. Small intestine dysfunction in Parkinson's disease. J Neural Transm 2015;122:16591661.

98. Fasano A, Bove F, Gabrielli M, et al. The role of small intestinal bacterial overgrowth in Parkinson's disease. Mov Disord 2013;28(9):1241-1249.

99. Tan AH, Mahadeva S, Thalha AM, et al. Small intestinal bacterial overgrowth in Parkinson's disease. Parkinsonism Relat Disord 2014;20(5):535-540.

100. Niu XL, Liu L, Song ZX, et al. Prevalence of small intestinal bacterial overgrowth in Chinese patients with Parkinson's disease. J Neural Transm (Vienna) 2016;123(12):1381-1386.

101. Vizcarra JA, Wilson-Perez HE, Fasano A, Espay AJ. Small intestinal bacterial overgrowth in Parkinson's disease: tribulations of a trial. Parkinsonism Relat Disord 2018;54:110-112.

102. DiBaise JK, Crowell MD, Driver-Dunckley E, et al. Weight loss in Parkinson's disease: no evidence for role of small intestinal bacterial overgrowth. J Parkinsons Dis 2018;8(4):571-581.

103. van Kessel SP, Frye AK, El-Gendy AO, et al. Gut bacterial tyrosine decarboxylases restrict levels of levodopa in the treatment of Parkinson's disease. Nat Commun 2019;10(1): 310. https://doi. org/10.1038/s41467-019-08294-y.

104. Pfeiffer RF. Management of autonomic dysfunction in Parkinson's disease. Semin Neurol 2017;37:176-185.

105. Knudsen K, Krogh K, Østergaard K, Borghammer P. Constipation in Parkinson's disease: subjective symptoms, objective markers, and new perspectives. Mov Disord 2017;32(1):94-105.

106. Jost WH, Schimrigk K. Constipation in Parkinson's disease. Klin Wochenschr 1991;69(20):906-909.

107. Savica R, Carlin JM, Grossardt BR, et al. Medical records documentation of constipation preceding Parkinson disease: a casecontrol study. Neurology 2009;73(21):1752-1758.

108. Svensson E, Henderson VW, Borghammer P, Horváth-Puhó E, Sørensen HT. Constipation and risk of Parkinson's disease: a Danish population-based cohort study. Parkinsonism Relat Disord 2016;28:18-22.

109. Lin $\mathrm{CH}$, Lin JW, Liu YC, Chang CH, Wu RM. Risk of Parkinson's disease following severe constipation: a nationwide population-based cohort study. Parkinsonism Relat Disord 2014;20(12):1371-1375.

110. Berg D, Postuma RB, Adler CH, et al. MDS research criteria for prodromal Parkinson's disease. Mov Disord 2015;30(12):16001609.

111. Armstrong MJ, Okun MS. Diagnosis and treatment of Parkinson disease. A review. JAMA 2020;323(6):548-560.

112. Toebosch S, Tudyka V, Masclee A, Koek G. Treatment of recurrent sigmoid volvulus in Parkinson's disease by percutaneous 
endoscopic colostomy. World J Gastroenterol 2012;18(40):58125815.

113. Blackley S, Maguire C, Daniels T. Seven cases of sigmoid volvulus in Parkinson's disease. J R Coll Physicians Edinb 2016;46(3): 157-159.

114. Van Laar T, Boertien JM, Horta Herranz A. Faecal transplantation, pro- and prebiotics in Parkinson's disease; hope or hype? J Parkinsons Dis 2019;9(s2):S371-S379.

115. Barichella M, Pacchetti C, Bolliri C, et al. Probiotics and prebiotic fiber for constipation associated with Parkinson disease: an RCT. Neurology 2016;87(12):1274-1280.

116. Freitas ME, Alqaraawi A, Lang AE, Liu LWC. Linaclotide and prucalopride for management of constipation in patients with parkinsonism. Mov Disord Clin Pract 2018;5(2):218-220.

117. Omer A, Quigley EMM. An update on prucalopride in the treatment of chronic constipation. Ther Adv Gastroenterol 2017;10(11):877-887.

118. Ondo WG, Kenney C, Sullivan K, et al. Placebo-controlled trial of lubiprostone for constipation associated with Parkinson disease. Neurology 2012;78(21):1650-1654.

119. Sakakibara R, Doi H, Sato M, et al. Nizatidine ameliorates slow transit constipation in Parkinson's disease. J Am Geriatr Soc 2015;63(2):399-401.

120. Parkinson Study Group. A randomized trial of relamorelin for constipation in Parkinson's disease (MOVE-PD): trial results and lessons learned. Parkinsonism Relat Disord 2017;37:101-105.

121. Sadjadpour K. Pyridostigmine bromide and constipation in Parkinson's disease. JAMA 1983;249(9):1148.

122. Pagano G, Tan EE, Haider JM, Bautista A, Tagliati M. Constipation is reduced by beta-blockers and increased by dopaminergic medications in Parkinson's disease. Parkinsonism Relat Disord 2015;21(2):120-125.

123. Chiu CM, Wang CP, Sung WH, Huang SF, Chiang SC, Tsai PY. Functional magnetic stimulation in constipation associated with Parkinson's disease. J Rehabil Med 2009;41(13):1085-1089.

124. McClurg D, Walker K, Aitchison P, et al. Abdominal massage for the relief of constipation in people with Parkinson's: a qualitative study. Parkinsons Dis 2016;2016:4842090.

125. Cersosimo MG, Raina GB, Pecci C, et al. Gastrointestinal manifestations in Parkinson's disease: prevalence and occurrence before motor symptoms. J Neurol 2013;260(5):1332-1338.

126. Bassotti G, Maggio D, Battaglia E, et al. Manometric investigation of anorectal function in early and late stage Parkinson's disease. J Neurol Neurosurg Psychiatry 2000;68(6):768-770.

127. Tateno F, Sakakibara R, Yokoi Y, et al. Levodopa ameliorated anorectal constipation in de novo Parkinson's disease: the QLGAT study. Parkinsonism Relat Disord 2011;17(9):662-666.

128. Edwards LL, Quigley EM, Harned RK, Hofman R, Pfeiffer RF. Defecatory function in Parkinson's disease: response to apomorphine. Ann Neurol 1993;33(5):490-493.

129. Albanese A, Brisinda G, Bentivoglio AR, Maria G. Treatment of outlet obstruction constipation in Parkinson's disease with botulinum neurotoxin A. Am J Gastroenterol 2003;98(6):1439-1440.

130. Gourcerol G, Maltete D, Chastan N, Welter ML, Leroi AM, Derrey S. Does bilateral deep brain stimulation of the subthalamic nucleus modify ano-rectal motility in Parkinson's disease? Results of a randomized cross-over study. Neuromodulation 2019;22(4): 478-483.

131. McDonald C, Winge K, Burn DJ. Lower urinary tract symptoms in Parkinson's disease: prevalence aetiology and management. Parkinsonism Relat Disord 2017:35:8-16.

132. Kitta T, Yabe I, Kanno Y, et al. Long-term outcome of adenosine A2A receptor antagonist on lower urinary tract symptoms in male Parkinson disease patients. Clin Neuropharmacol 2018:41:98102
133. Roy HA, Griffiths DJ, Aziz TZ, Green AL, Menke RAL. Investigation of urinary storage symptoms in Parkinson's disease utilizing structural MRI techniques. NeurourolUrodyn 2019;38(4):1168-1175.

134. Vurture G, Peyronnet B, Feigin A, et al. Outcomes of intradetrusor onabotulinum toxin A ijection in patients with Parkinson's disease. NeurourolUrodyn 2018;37(8):2669-2677.

135. Gubbiotti M, Conte A, Di Stasi SM, Tambasco N, Giannantoni A. Feasibility of mirabegron in the treatment of overactive bladder in patients affected by Parkinson's disease: a pilot study. Ther Adv Neurol Disord 2019;12:1-9.

136. Hajebrahimi S, Chapple CR, Pashazadeh F, Salehi-Pourmehr H. Management of neurogenic bladder in patients with Parkinson's disease: a systematic review. NeurourolUrodyn 2019;38(1):31-62.

137. Martinez-Martin P, Schapira AH, Stocchi F, et al. Prevalence of nonmotor symptoms in Parkinson's disease in an international setting; study using nonmotor symptoms questionnaire in 545 patients. Mov Disord 2007;22(11):1623-1629.

138. O'Sullivan SS, Williams DR, Gallagher DA, Massey LA, Silveira-Moriyama L, Lees AJ. Nonmotor symptoms as presenting complaints in Parkinson's disease: a clinicopathological study. Mov Disord 2008;23(1):101-106.

139. Sakakibara R, Tateno F, Kishi M, Tsuyuzaki Y, Uchiyama T, Yamamoto T. Pathophysiology of bladder dysfunction in Parkinson's disease. Neurobiol Dis 2012;46(3):565-571.

140. Sakakibara R, Panicker J, Finazzi-Agro E, Iacovelli V, Bruschini H, The Parkinson's Disease Subcommittee, The Neurourology Promotion Committee in The International Continence Society. A guideline for the management of bladder dysfunction in Parkinson's disease and other gait disorders. NeurourolUrodyn 2016;35(5):551-563.

141. Winge K, Fowler CJ. Bladder dysfunction in Parkinsonism: mechanisms, prevalence, symptoms, and management. Mov Disord 2006;21(6):737-745

142. Singer C, Moore H. Urological dysfunction. In: Pfeiffer RF, Wszolek ZK, Ebadi M, eds. Parkinson's disease, 2 Boca Raton: CRC Press; 2013:327-341.

143. Ragab MM, Mohammed ES. Idiopathic Parkinson's disease patients at the urologic clinic. NeurourolUrodyn 2011;30(7):12581261.

144. Vurture G, Peyronnet B, Palma J-A, et al. Urodynamic mechanisms underlying overactive bladder symptoms in patients with Parkinson disease. Int Neurourol J 2019;23(3):211-218.

145. Moore H, Singer C. Urological dysfunction. In: Pfeiffer RF, Bodis-Wollner I, eds. Parkinson's disease and nonmotor dysfunction, 2 New York: Humana Press; 2013:187-200.

146. Pavlakis AJ, Siroky MB, Goldstein I, Krane RJ. Neurourologic findings in Parkinson's disease. J Urol 1983;129(1):80-83.

147. Galloway NT. Urethral sphincter abnormalities in Parkinsonism. Br J Urol 1983;55(6):691-693.

148. Sakakibara R, Lee F-C, Suzuki H, Tateno F, Kishi M, Aiba Y. Parkinson's disease and prostate enlargement: both contribute to overactive bladder in the elderly. Int J Urol 2018;25(11):982-983.

149. Vaughan CP, Burgio KL, Goode PS, et al. Behavioral therapy for urinary symptoms in Parkinson's disease: a randomized clinical trial. NeurourolUrodyn 2019;38(6):1737-1744.

150. McDonald C, Rees J, Winge K, Newton JL, Burn DJ. Bladder training for urinary tract symptoms in PD: a randomized controlled trial. Neurology 2020;94(13):e1427-e1433.

151. Kay GG, Ebinger U. Preserving cognitive function for patients with overactive bladder: evidence for a differential effect with darifenacin. Int J Clin Pract 2008;62(11):1792-1800.

152. Batla A, Tayim N, Pakzad M, Panicker JN. Treatment options for urogenital dysfunction in Parkinson's disease. Curr Treat Options Neurol 2016;18(10):45 https://doi.org/10. 1007/s11940-016-0427-0. 
153. Zesiewicz TA, Evatt M, Vaughan CP, et al. Non-Motor Working Group of the Parkinson Study Group (PSG). Randomized, controlled pilot trial of solifenacin succinate for overactive bladder in Parkinson's disease. Parkinsonism Relat Disord 2015;21(5):514520.

154. Peyronnet B, Vurture G, Palma J-A, et al. Mirabegron in patients with Parkinson disease and overactive bladder symptoms: a retrospective cohort. Parkinsonism Relat Disord 2018;57:22-26.

155. Brusa L, Ponzo V, Stefani A, et al. Extended release levodopa at bedtime as a treatment for nocturia in Parkinson's disease: an open label study. J Neurol Sci 2020;410:116625. https://doi.org/10. 1016/j.jns.2019.116625.

156. Kulaksizoglu H, Parman Y. Use of botulinum toxin-A for the treatment of overactive bladder symptoms in patients with Parkinson's disease. Parkinsonism Relat Disord 2010;16(8):531534.

157. Giannantoni A, Conte A, Proietti S, et al. Botulinum toxin type A in patients with Parkinson's disease and refractory overactive bladder. J Urol 2011;186(3):960-964.

158. McClurg D, Panicker J, Walker RW, et al. Stimulation of the tibial nerve: a protocol for a multicentred randomised controlled trial for urinary problems associated with Parkinson's disease STARTUP. BMJ Open 2020;10(2):e034887. https://doi.org/10. 1136/bmjopen-2019-034887.

159. Mock S, Osborn DJ, Brown ET, et al. The impact of pallidal and subthalamic deep brain stimulation on urologic function in Parkinson's disease. Neuromodulation 2016;19(7):717-723.

160. Zong H, Meng F, Zhang Y, Wei G, Zhao H. Clinical study of the effects of deep brain stimulation on urinary dysfunctions in patients with Parkinson's disease. Clin Interv Aging 2019;14: 11591166. https://doi.org/10.2147/CIA.S204368.

161. Stocchi F, Carbone A, Inghilleri M, et al. Urodynamic and neurophysiological evaluation in Parkinson's disease and multiple system atrophy. J Neurol Neurosurg Psychiatry 1997;62(5):507-511.

162. Seth J, Rintoul-Hoad S, Sahai A. Urethral sphincter injection of botulinum toxin A: a review of its application and outcomes. Low Urin Tract Symptoms 2018;10(2):109-115.

163. van Hees PJ, van der Plas AA, van Ek GF, et al. Discussing sexuality with patients with Parkinson's disease: a survey among Dutch neurologists. J Neural Transm (Vienna) 2017;124(3):361368.

164. Jitkritsadakul O, Jagota P, Bhidayasiri R. Postural instability, the absence of sexual intercourse in the past month, and loss of libido are predictors of sexual dysfunction in Parkinson's disease. Parkinsonism Relat Disord 2015;21(1):61-67.

165. Koller WC, Vetere-Overfield B, Williamson A, Busenbark K, Nash J, Parrish D. Sexual dysfunction in Parkinson's disease. Clin Neuropharmacol 1990;13(5):461-463.

166. Pfeiffer RF. Gastrointestinal, urological, and sexual dysfunction in Parkinson's disease. Mov Disord 2010;25(Suppl 1):S94-S97.

167. Shalash A, Hamid E, Elrassas H, Abushouk AI, Salem HH. Sexual dysfunction in male patients with Parkinson's disease: related factors and impact on quality of life. Neurol Sci 2020: https://doi.org/ 10.1007/s10072-020-04328-2.

168. Deng X, Xiao B, Li HH, et al. Sexual dysfunction is associated with postural instability gait difficulty subtype of Parkinson's disease. J Neurol 2015;262(11):2433-2439.

169. Bronner G, Israeli-Korn S, Hassin-Baer S, Yahalom G. Acquired premature ejaculation in Parkinson's disease and possible mechanisms. Int J Impot Res 2018;30(4):153-157.

170. Ferrucci R, Panzeri M, Ronconi L, et al. Abnormal sexuality in Parkinson's disease: fact or fancy? J Neurol Sci 2016;369:5-10.

171. Zhao S, Wang J, Xie Q, et al. Parkinson's disease is associated with risk of sexual dysfunction in men but not in women: a systematic review and meta-analysis. J Sex Med 2019;16:434-446.
172. Mitidieri E, Cirino G, d'Emmanuele di Villa Bianca R, Sorrentino R. Pharmacology and perspectives in erectile dysfunction in man. Pharmacol Ther 2020;208:107493. https://doi.org/10.1016/j. pharmthera.2020.107493.

173. Zesiewicz TA, Helal M, Hauser RA. Sildenafil citrate (Viagra) for the treatment of erectile dysfunction in men with Parkinson's disease. Mov Disord 2000;15(2):305-308.

174. Hussain IF, Brady CM, Swinn MJ, Mathias CJ, Fowler CJ. Treatment of erectile dysfunction with sildenafil citrate (Viagra) in parkinsonism due to Parkinson's disease or multiple system atrophy with observations on orthostatic hypotension. J Neurol Neurosurg Psychiatry 2001;71(3):371-374.

175. Bernard BA, Verhagen Metman L, Levine L, Ouyang B, Leurgans S, Goetz CG. Sildenafil in the treatment of erectile dysfunction in Parkinson's disease. Mov Disord Clin Pract 2016;4(3):412-415.

176. Okun MS, McDonald WM, DeLong MR. Refractory nonmotor symptoms in male patients with Parkinson disease due to testosterone deficiency: a common unrecognized comorbidity. Arch Neurol 2002;59(5):807-811.

177. Simonsen U, Comerma-Steffensen S, Andersson KE. Modulation of dopaminergic pathways to treat erectile dysfunction. Basic Clin Pharmacol Toxicol 2016;119(Suppl 3):63-74.

178. Bronner G, Korczyn AD. The role of sex therapy in the management of patients with Parkinson's disease. Mov Disord Clin Pract 2017;5(1):6-13.

179. Bronner G, Aharon-Peretz J, Hassin-Baer S. Sexuality in patients with Parkinson's disease, Alzheimer's disease, and other dementias. Handb Clin Neurol 2015;130:297-323.

180. Bronner G, Hassin-Baer S, Gurevich T. Sexual preoccupation behavior in Parkinson's disease. J Parkinsons Dis 2017;7(1):175182.

181. Aquino CC, Mestre T, Lang AE. Restless genital syndrome in Parkinson disease. JAMA Neurol 2014;71(12):1559-1561.

182. Lefaucheur R, Berthelot L, Sénant J, Borden A, Maltête D. Acute genital pain during non-motor fluctuations improved by apomorphine. Mov Disord 2013;28(5):687-688.

183. Skorvanek M, Bhatia KP. The skin and Parkinson's disease: review of clinical, diagnostic, and therapeutic issues. Mov Disord Clin Pract 2016;4(1):21-31.176.

184. Coon EA, Low PA. Thermoregulation in Parkinson disease. Handb Clin Neurol 2018;157:715-725.

185. Pont-Sunyer C, Hotter A, Gaig C, et al. The onset of nonmotor symptoms in Parkinson's disease (the ONSET PD study). Mov Disord 2015;30(2):229-237.

186. Langston JW, Forno LS. The hypothalamus in Parkinson disease. Ann Neurol 1978;3(2):129-133.

187. Beach TG, Adler CH, Sue LI, et al; Arizona Parkinson's Disease Consortium. Multi-organ distribution of phosphorylated alphasynuclein histopathology in subjects with Lewy body disorders. Acta Neuropathol 2010;119(6):689-702.

188. Gelpi E, Navarro-Otano J, Tolosa E, et al. Multiple organ involvement by alpha-synuclein pathology in Lewy body disorders. Mov Disord 2014;29(8):1010-1018.

189. Ramirez-Zamora A, Smith H, Youn Y, Durphy J, Shin DS, Pilitsis JG. Hyperhidrosis associated with subthalamic deep brain stimulation in Parkinson's disease: insights into central autonomic functional anatomy. J Neurol Sci 2016;366:59-64.

190. Kataoka H, Ueno S. Severe cold lower limbs in patients with Parkinson's disease during the summer. Neurol Int 2016;8(4): 6676.

191. Shindo K, Kobayashi F, Miwa M, Nagasaka T, Takiyama Y, Shiozawa Z. Temporal prolongation of decreased skin blood flow causes cold limbs in Parkinson's disease. J Neural Transm (Vienna) 2013;120(3):445-451.

192. Snider SR, Fahn S, Isgreen WP, Cote LJ. Primary sensory symptoms in parkinsonism. Neurology 1976;26(5):423-429. 
193. De Marinis M, Stocchi F, Testa SR, De Pandis F, Agnoli A. Alterations of thermoregulation in Parkinson's disease. Funct Neurol 1991;6(3):279-283.

194. Turkka JT, Myllylä VV. Sweating dysfunction in Parkinson's disease. Eur Neurol 1987;26(1):1-7.

195. Swinn L, Schrag A, Viswanathan R, Bloem BR, Lees A, Quinn N. Sweating dysfunction in Parkinson's disease. Mov Disord 2003;18(12):1459-1463.

196. Lipp A, Sandroni P, Ahlskog JE, et al. Prospective differentiation of multiple system atrophy from Parkinson disease, with and without autonomic failure. Arch Neurol 2009;66(6):742-750.

197. Pursiainen V, Haapaniemi TH, Korpelainen JT, Sotaniemi KA, Myllylä VV. Sweating in Parkinsonian patients with wearingoff. Mov Disord 2007;22(6):828-832.

198. Sage JI, Mark MH. Drenching sweats as an off phenomenon in Parkinson's disease: treatment and relation to plasma levodopa profile. Ann Neurol 1995;37(1):120-122.

199. van Wamelen DJ, Leta V, Podlewska AM, et al. Exploring hyperhidrosis and related thermoregulatory symptoms as a possible clinical identifier for the dysautonomic subtype of Parkinson's disease. J Neurol 2019;266:1736-1742.

200. Keyser DL, Rodnitzky RL. Neuroleptic malignant syndrome in Parkinson's disease after withdrawal or alteration of dopaminergic therapy. Arch Intern Med 1991;151(4):794-796.

201. Serrano-Duenas M. Neuroleptic malignant syndrome-like, or dopaminergic malignant syndrome - due to levodopa therapy withdrawal. Clinical features in 11 patients. Parkinsonism Relat Disord 2003;9(3):175-178.

202. Ladha SS, Walker R, Shill HA. Case of neuroleptic malignant-like syndrome precipitated by abrupt fava bean discontinuance. Mov Disord 2005;20(5):630-631.

203. Bonnici A, Ruiner CE, St-Laurent L, Hornstein D. An interaction between levodopa and enteral nutrition resulting in neuroleptic malignant-like syndrome and prolonged ICU stay. Ann Pharmacother 2010;44(9):1504-1507.

204. Whitman CB, Ablordeppy E, Taylor B. Levodopa withdrawal presenting as fever in a critically ill patient receiving concomitant enteral nutrition. J Pharm Pract 2016;29(6):574-578.

205. Pfeiffer RF, Sucha EL. "On-off'-induced lethal hyperthermia. Mov Disord 1989;4(4):338-341.

206. Trachani E, Constantoyannis C, Sirrou V, Kefalopoulou Z, Markaki E, Chroni E. Effects of subthalamic nucleus deep brain stimulation on sweating function in Parkinson's disease. Clin Neurol Neurosurg 2010;112(3):213-217.

207. Sanghera MK, Ward C, Stewart RM, Mewes K, Simpson RK, Lai EC. Alleviation of drenching sweats following subthalamic deep brain stimulation in a patient with Parkinson's disease - a case report. J Neurol Sci 2009;285(1-2):246-249.

Publisher's Note Springer Nature remains neutral with regard to jurisdictional claims in published maps and institutional affiliations. 